\title{
A study evaluating knowledge of and attitude towards hepatitis B among pregnant women at a teaching hospital in Nellore, India
}

\author{
Swetha Munivenkatappa ${ }^{1}$, Srinivas M. Govindaraj ${ }^{2 *}$
}

\begin{abstract}
${ }^{1}$ Department of Obstetrics and Gynecology, ${ }^{2}$ Department of Medical Gastroenterology, Narayana Medical College, Chintareddypalem, Nellore, Andhra Pradesh, India
\end{abstract}

Received: 03 July 2019

Accepted: 17 July 2019

\author{
*Correspondence: \\ Dr. Srinivas MG, \\ E-mail: drmgsri@yahoo.co.in
}

Copyright: () the author(s), publisher and licensee Medip Academy. This is an open-access article distributed under the terms of the Creative Commons Attribution Non-Commercial License, which permits unrestricted non-commercial use, distribution, and reproduction in any medium, provided the original work is properly cited.

\begin{abstract}
Background: Hepatitis B infection is a common and preventable infection in India. Mother to child transmission is the most common method of infection in our country. Awareness regarding hepatitis B among pregnant women is important to take preventive measures like screening during pregnancy, vaccination of child. Studies evaluating knowledge, attitude and practice (KAP) towards hepatitis B among the pregnant women in our country are sparse.

Methods: A cross sectional survey was conducted to evaluate KAP towards hepatitis B among pregnant women was conducted after handing over an information hand-out. Data was collected using a standard questionnaire with three sections: i) Demographic data ii) Knowledge questions iii) Attitude and Practice questions.

Results: $42 \%$ of the 350 participants were aware about hepatitis B infection. The mean knowledge score was 6.33 $( \pm 2.86)$. Only $33.3 \%$ were aware that hepatitis B is transmitted by unprotected sex and $8.2 \%$ were knowledgeable of mother to child transmission. The mean attitude/practice score was $2.97( \pm 1.69)$. Only $30 \%$ would insist on safe equipment and blood/blood products. $84 \%$ would hesitate to have casual contact with hepatitis B infected persons. Most feared the stigma associated with hepatitis $\mathrm{b}$ infection than its health consequences. $70 \%$ would vaccinate their child to prevent hepatitis B infection. Women with greater knowledge about hepatitis B had better attitude/practice towards its prevention.

Conclusions: Knowledge about HBV among pregnant women was poor and needs to be improved to prevent mother to child transmission. Educational programs need to be tailored for the target population for better uptake.
\end{abstract}

Keywords: Attitude, Hepatitis B, India, Knowledge, Practice, Pregnant women

\section{INTRODUCTION}

Hepatitis B infection is common, potentially lethal (cirrhosis and hepatocellular carcinoma) and most importantly preventable infection. About two billion are infected with $\mathrm{HBV}$ and 350 million are chronically infected. Prevalence of $\mathrm{HBV}$ infection in India is estimated to be between 3 to $4.2 \%$. $^{1}$ Among the mothers, prevalence reported ranges from 0.61 to $10.2 \%$, with most reporting around $2 \%{ }^{2}$ Perinatal infection of $\mathrm{HBV}$ remains an important mode of transmission in developing countries and perinatal infection is more likely to result in chronic infection and long term infection also increases the risk of cirrhosis and HCC. About one in 25 children born in India develop chronic hepatitis B infection. ${ }^{3}$ Screening and vaccination of all pregnant women, antiviral therapy in mothers with high viral load, perinatal interventions (hepatitis $b$ immunoglobulin and HBV vaccination) for the newborns of infected mothers can prevent a significant number of new infections. ${ }^{4}$ Hepatitis $B$ vaccination is part of universal immunization program in India since 2002. However, the coverage was only $53 \%$ in 2017 and $88 \%$ completed all three doses. ${ }^{5}$ Knowledge, Attitude and Practice studies are tools used to study health seeking behaviour studies. Knowledge evaluates patients understanding of biomedical concepts. 
Attitude is a learned predisposition to think, feel and act in a particular way towards a given object or class of objects. Practice inquiries about peoples' behaviour in a particular health scenario. Good knowledge, attitude and practice towards a disease is essential to reduce the effect of a disease in the society. Only $4 \%$ of women in childbearing age had heard about hepatitis $\mathrm{B}$ infection in Mumbai city. ${ }^{6}$ In this study authors aim to assess the knowledge, attitude and practice of pregnant woman attending ante-natal clinics in our hospital. The findings will help in developing targeted interventions to prevent hepatitis $\mathrm{B}$ transmission.

\section{METHODS}

\section{Inclusion criteria}

Pregnant women aged more than 18 years and attending ante-natal care clinic at Narayana Medical College and Hospital, Nellore, India.

\section{Exclusion criteria}

Those not consenting to participate in study. Those who could not understand Telugu language.

\section{Study period}

1st April 2019 to 30th April 2019.

\section{Methodology}

A hand-out with information on 'hepatitis b' was given to all women coming to ante-natal clinic at the time of registration at front desk. Data was collected using a standard questionnaire after their ante-natal checkup. All pregnant women aged more than 18 years were approached and data was collected from those who chose to participate in the study and provide an informed written consent. The study was approved by the Institutional ethics committee. No data which could be used to trace the identity of participants were collected.

The questionnaire was first prepared in English and translated to Telugu then checked using English back translation. The questions were based on other similar studies. ${ }^{7,8}$ The questionnaire was pre-tested on 10 patients to check the comprehension of the questions and some modifications were done to simplify the questionnaire.

Data from the pilot study was not included in the study. The questionnaire had three sections: i) Demographic data (6 questions) ii) Knowledge questions (18 questions) iii) Attitude and Practice questions (10 questions). Women who agreed to participate in study were initially asked 'do you know about a disease called Hepatitis B?' Further questions were administered only if they replied as 'yes'. Those who answered in negative were not included in the analysis. Further questions were to be answered in yes/no and multiple choice format. Each correct answer was given one point and incorrect answer got no points.

\section{Statistics}

All analysis was performed using SPSS v21 statistics software. Categorical variables were measured as percentages and continuous variables were expressed as mean \pm standard deviation.

Kruskal Wallis test was used to assess significance among study variables. Spearmans correlation coefficient was used to evaluate association between knowledge and attitude/practice. Degree of statistical significance was declared at a $p$ value $\leq 0.05$

\section{RESULTS}

A total of 350 pregnant woman agreed to participate in the study. Of them only 147 (42\%) answered the question 'do you know about a disease called Hepatitis B' as 'yes'. The demographic characteristics of these participants are presented in Table 1.

Table 1: Demographic characteristics of the study participants $(\mathrm{N}=147)$.

\begin{tabular}{|c|c|c|}
\hline Characteristics & $\mathbf{N}$ & $\%$ \\
\hline \multicolumn{3}{|c|}{ Age in years $(23.35 \pm 3.63)$} \\
\hline$\leq 20(19.6 \pm 0.68)$ & 30 & 20.4 \\
\hline $21-25(22.69 \pm 1.29)$ & 90 & 61.2 \\
\hline $26-30(27.94 \pm 1.16)$ & 18 & 12.2 \\
\hline$>30(33.22 \pm 1.79)$ & 9 & 6.1 \\
\hline \multicolumn{3}{|l|}{ Education } \\
\hline Illiterate & 6 & 4.1 \\
\hline Primary & 4 & 2.7 \\
\hline Middle & 12 & 8.2 \\
\hline High & 29 & 19.7 \\
\hline College & 96 & 65.3 \\
\hline \multicolumn{3}{|l|}{ Occupation } \\
\hline None & 130 & 88.4 \\
\hline Agriculture/laborer & 11 & 7.5 \\
\hline Others & 6 & 4.1 \\
\hline \multicolumn{3}{|l|}{ No. of children } \\
\hline 0 & 84 & 57.1 \\
\hline 1 & 60 & 40.8 \\
\hline 2 & 3 & 2 \\
\hline \multicolumn{3}{|l|}{ Trimester } \\
\hline 1 & 52 & 35.4 \\
\hline 2 & 51 & 34.7 \\
\hline 3 & 44 & 29.9 \\
\hline \multicolumn{3}{|c|}{ Socio-economic status } \\
\hline Lower & 10 & 6.8 \\
\hline Lower-middle & 41 & 27.9 \\
\hline Middle & 66 & 44.9 \\
\hline Upper-middle & 28 & 19 \\
\hline Upper & 02 & 1.4 \\
\hline
\end{tabular}


The mean age of the participants was $23.35 \pm 3.63$ years with most of them being less than 25 years old. Nearly a third were educated to college level.

However, $88.4 \%$ reported not to be employed. $91.8 \%$ fell in the mid income (lower middle, middle and upper middle) category. $57 \%$ were primigravida and $41 \%$ had one child at the time of survey. There was almost equal representation from all three trimesters of pregnancy.

\section{Assessment of knowledge towards Hepatitis B}

Knowledge status regarding hepatitis B infection among the pregnant women is shown in Table 2.

Table 2: Response to knowledge assessment questions.

\begin{tabular}{|c|c|c|}
\hline Questions & Correct (no.) & Correct $(\%)$ \\
\hline Can Hepatitis B infection cause liver disease? & 62 & 42.2 \\
\hline Can Hepatitis B infection cause liver cancer? & 54 & 36.7 \\
\hline Can Hepatitis B infection occur at any age? & 62 & 42.2 \\
\hline Hepatitis B can cause jaundice? & 55 & 37.4 \\
\hline Hepatitis B infection can cause loss of appetite, nausea, vomiting? & 45 & 30.6 \\
\hline Many persons infected with Hepatitis B have no symptoms? & 54 & 36.7 \\
\hline Hepatitis B can be transmitted by handshake or cough? & 47 & 32 \\
\hline $\begin{array}{l}\text { Hepatitis B can be transmitted by unsterilized needles, syringes, blood and blood } \\
\text { products? }\end{array}$ & 58 & 39.5 \\
\hline $\begin{array}{l}\text { Hepatitis B can be transmitted by blades at barber shop and by ear/nose } \\
\text { piercing/tattoo? }\end{array}$ & 52 & 35.4 \\
\hline Hepatitis b can be transmitted by unsafe sex (not using condoms)? & 49 & 33.3 \\
\hline Hepatitis B can be transmitted from mother to child? & 12 & 8.2 \\
\hline $\begin{array}{l}\text { Hepatitis B can be transmitted by sharing food/utensils with persons infected with } \\
\text { Hepatitis B? }\end{array}$ & 50 & 34 \\
\hline Hepatitis B can be treated and controlled? & 33 & 22.4 \\
\hline Some people may be able to clear Hepatitis B infection from their body? & 65 & 44.2 \\
\hline Effective vaccines are available for protection from Hepatitis B? & 52 & 35.4 \\
\hline Persons infected with Hepatitis B must follow specific diet? & 22 & 15 \\
\hline As a pregnant woman, you should be tested for Hepatitis B infection? & 63 & 42.9 \\
\hline Your infant should receive Hepatitis B vaccination? & 64 & 43.5 \\
\hline
\end{tabular}

Note: Knowledge was assessed by giving 1 to correct answer and 0 to the wrong answer. The scale measured knowledge from maximum 18 to minimum 0 .

Respondents had poor knowledge regarding symptoms (responses to Q4-6), transmission (responses to Q7-12) and treatment and prevention (responses to Q13-18) of hepatitis B. Correct response rates were $37.4 \%, 30.6 \%$ and $36.7 \%$ for symptom related questions. It was $32 \%$, $39.5 \%, 35.4 \%, 33.3 \%, 8.2 \%$ and $34 \%$ for transmission related questions and $22.4 \%, 44.2 \%, 35.4 \%, 15 \%, 42.9 \%$ and $43.5 \%$ for treatment and prevention related questions. The mean knowledge score was $6.33( \pm 2.86)$ out of a maximum 18. There was no significant difference in the knowledge scores between the sub-groups of age, education, occupation, socio-economic status, number of children or trimester of pregnancy (Table 3 ).

\section{Assessment of attitude and practice towards Hepatitis B}

Attitude and practice towards hepatitis B was assessed with 10 questions. (Table4) A positive attitude/practice was scored 1 and negative attitude/practice. Only $15.6 \%$ believed that even they are vulnerable to get infected with hepatitis B. $91 \%$ were afraid of societal discrimination rather than the health consequences of the infection. Only about $30 \%$ would insist on safe equipment and blood/blood products. Majority (86\%) of them would hesitate to co-habit, work or share food/utensils with hepatitis $b$ infected persons, even more if it concerns their children (95\%). Thirty-four (23\%) were aware that they have been screened for hepatitis B infection. $73 \%$ were ready to vaccinate their child to protect against hepatitis $\mathrm{B}$ infection. About $71 \%$ were keen to attend educational programs to learn more about hepatitis B infection. The mean attitude/practice score was $2.97( \pm 1.69)$ out of a maximum 10. There was no significant difference in the attitude/practice scores between the sub-groups of age, education, occupation, socio-economic status, number of children or trimester of pregnancy (Table 3 ). 
Spearman rank correlation revealed weak positive but insignificant correlation between education-knowledge ( $\mathrm{r}$ $=0.153, \mathrm{p}=0.06)$. There was a significant positive correlation between knowledge-attitude/practice $(\mathrm{r}=0.384, \mathrm{p}=0.000)$. This result highlights the relationship between knowledge attitude and practice in disease control interventions.

Table 3: Knowledge and attitude scores according to demographic characteristics.

\begin{tabular}{|c|c|c|c|c|}
\hline Characteristics & Knowledge score & Significance $(\mathbf{p})^{*}$ & Attitude score & Significance $(p) *$ \\
\hline Age in years & $6.33( \pm 2.86)$ & & $2.97( \pm 1.69)$ & \\
\hline$\leq 20$ & $6.17( \pm 2.98)$ & 0.26 & $3.17( \pm 1.42)$ & 0.63 \\
\hline $21-25$ & $6.64( \pm 2.50)$ & & $2.98( \pm 1.59)$ & \\
\hline $26-30$ & $6.11( \pm 3.10)$ & & $3.11( \pm 1.91)$ & \\
\hline$>30$ & $4.11( \pm 4.43)$ & & $2( \pm 2.4)$ & \\
\hline Education & & 0.28 & & 0.99 \\
\hline Illiterate & $4.67( \pm 2.73)$ & & $3.00( \pm 1.67)$ & \\
\hline Primary & $5.75( \pm 4.19)$ & & $3.50( \pm 3.11)$ & \\
\hline Middle & $6.00( \pm 3.08)$ & & $2.92( \pm 1.78)$ & \\
\hline High & $5.72( \pm 3.17)$ & & $2.83( \pm 1.79)$ & \\
\hline College & $6.68( \pm 2.66)$ & & $3.00( \pm 1.53)$ & \\
\hline \multicolumn{5}{|l|}{ Occupation } \\
\hline None & $6.35( \pm 2.82)$ & 0.77 & $2.99( \pm 1.64)$ & 0.68 \\
\hline Agriculture/laborer & $6.27( \pm 3.55)$ & & $2.55( \pm 1.7)$ & \\
\hline Others & $5.83( \pm 2.64)$ & & $3.33( \pm 1.75)$ & \\
\hline \multicolumn{5}{|l|}{ No. of children } \\
\hline 0 & $6.11( \pm 3.29)$ & 0.8 & $2.92( \pm 1.81)$ & 0.87 \\
\hline 1 & $6.6( \pm 2.16)$ & & $3.05( \pm 1.38)$ & \\
\hline 2 & $7( \pm 1.73)$ & & $3( \pm 1.73)$ & \\
\hline \multicolumn{5}{|l|}{ Trimester } \\
\hline 1 & $6.25( \pm 2.62)$ & 0.56 & $3.19( \pm 1.48)$ & 0.43 \\
\hline 2 & $6.75( \pm 2.90)$ & & $3.02( \pm 1.68)$ & \\
\hline 3 & $5.93( \pm 3.06)$ & & $2.66( \pm 1.75)$ & \\
\hline \multicolumn{5}{|c|}{ Socio-economic status } \\
\hline Lower & $6.00( \pm 3.46)$ & 0.87 & $2.70( \pm 1.64)$ & 0.86 \\
\hline Lower-middle & $6.12( \pm 3.02)$ & & $2.80( \pm 1.69)$ & \\
\hline Middle & $6.56( \pm 2.92)$ & & $3.08( \pm 1.59)$ & \\
\hline Upper-middle & $6.25( \pm 2.38)$ & & $3.07( \pm 1.76)$ & \\
\hline Upper & $5.50( \pm 0.71)$ & & $3.00( \pm 1.41)$ & \\
\hline
\end{tabular}

*Kruskal Wallis test.

Table 4: Response to attitude/practice assessment questions.

\begin{tabular}{|c|c|c|}
\hline Questions & $\begin{array}{l}\text { Positive } \\
\text { response (no.) }\end{array}$ & $\begin{array}{l}\text { Positive } \\
\text { response }(\%)\end{array}$ \\
\hline Have you ever thought that you could get hepatitis B? & 23 & 15.6 \\
\hline $\begin{array}{l}\text { What would be your main concern if you were to be diagnosed with hepatitis B } \\
\text { infection? } *\end{array}$ & 13 & 8.8 \\
\hline Would you ask for safe equipment before ear/nose piercing/tattoo? & 49 & 33.3 \\
\hline Would you ask for screening before transfusion of blood or blood products? & 42 & 28.6 \\
\hline Would you worry/hesitate to work with a person with hepatitis B infection? & 21 & 14.3 \\
\hline Would you worry/hesitate to share food/utensils with a person infected with hepatitis B? & 19 & 12.9 \\
\hline Would you worry if your child is in the same class with a hepatitis B infected child? & 8 & 5.4 \\
\hline Do you think it is safe to vaccinate your child against hepatitis B? & 107 & 72.8 \\
\hline Have you done screening for hepatitis B infection? & 34 & 23.1 \\
\hline Would you like to participate in educational program regarding hepatitis B? & 104 & 70.7 \\
\hline
\end{tabular}

*Fear of death, Fear of spread to family members, Cost of treatment = positive attitude. Isolation from society = negative attitude. 


\section{DISCUSSION}

The present study shows that pregnant women have poor KAP towards hepatitis B. Only $42 \%$ were aware of a condition called hepatitis B in-spite of being provided with a hand-out with hepatitis B related information. Very few have knowledge of how hepatitis B can affect their health, its possible manifestations and modes of spread. This lack of knowledge leads to delayed health seeking behavior and continued transmission of hepatitis $\mathrm{B}$ in the society. These findings are consistent with reports of poor hepatitis B related knowledge from other studies. $^{6-8}$

The lack of knowledge was consistent across all strata of society regardless of age, education, occupation, income. It was poor even among those who were not primigravida and did not differ between the three trimesters, pointing to a missed opportunity to educate them at earlier points of contact. More worrying is the fact that awareness regarding the two most common modes of hepatitis $\mathrm{B}$ transmission - mother to child and sexual was only $8 \%$ and $33 \%$ respectively. Also $63 \%$ were not aware that infected mothers can be asymptomatic. Studies from China and Nigeria have reported higher awareness about HBV being transmitted by unprotected sexual contact (46.7\% and $41.2 \%)$ and from mother to child $(80 \%) .{ }^{9}, 10$ WHO strongly recommends universal screening of all pregnant women for HBV infection to reduce mother to child HBV transmission. ${ }^{11}$ It is not yet implemented by Government of India. Moreover $84.4 \%$ did not believe that they too can get infected with hepatitis B. This can explain why only $23 \%$ were aware of their screening status in this study.

This study also reveals the stigma associated with HBV infection. More than $85 \%$ were hesitant to work or share food/utensils with other hepatitis B patients. $95 \%$ were worried about their child if they were to be with another child with hepatitis B infection at school. This may be due to wrong belief that HBV is transmitted through casual contact like touch, cough (68\%) and fear of isolation in the society $(91 \%)$. There is also a possibility that HBV is confused with HIV leading to such irrational behavior. Similar beliefs about hepatitis B being transmitted by sharing food/utensils (55\%) and that other chronically infected hepatitis B patients are risk to other persons $(61 \%)$ are reported from Vietnamese studies. ${ }^{12}$ Such beliefs also affect the health related quality of life. ${ }^{13}$ Only a third of the participants were concerned about the precautions that need to be taken to prevent hepatitis B infection during tattooing, body piercing or receiving blood or blood products. More awareness needs to be created so that sufficient precautionary measures are taken at possible points of hepatitis B dissemination.

More than $70 \%$ of participants were willing to vaccinate their child against hepatitis B and to participate in educational programs to improve their understanding about hepatitis B. Correlation studies showed that good attitude/practice was strongly associated with greater knowledge and understanding of hepatitis B. Awareness regarding hepatitis $\mathrm{B}$ tended to be better in those with higher education. People with more education likely have greater access to information from various sources including mass media, internet, educational pamphlets, and healthcare professionals, and they are more likely to understand health information more readily. But it alone may not be adequate to achieve the intended level of effectiveness to stop mother to child transmission. These findings emphasize a necessity to improve education programs targeting women of childbearing age about HBV and the benefits of hepatitis B antenatal testing and hepatitis $\mathrm{B}$ vaccination. It is also necessary to tailor the antenatal educational programs and materials to ensure that key messages are effectively conveyed to the target audiences. Health care professionals should be the source of information regarding hepatitis B.

The limitation of our study is that most of the participants were educated to college level and may not be representative of the general population with varying levels of education. The KAP regarding hepatitis B may be overestimated and actually be worse in rural/less educated population.

\section{CONCLUSION}

The pregnant women in this study had insufficient knowledge and understanding about hepatitis B infection. It is more so in less educated individuals. Simple interventions like handing out an information hand-out may not be sufficient to improve the knowledge, attitude and practice regarding hepatitis $\mathrm{B}$, even among relatively educated individuals. More intensive and targeted approaches to deliver the appropriate information in a simplified and acceptable means needs to be implemented. Further studies are needed to evaluate the effectiveness of such interventions.

Funding: No funding sources

Conflict of interest: None declared

Ethical approval: The study was approved by the Institutional Ethics Committee

\section{REFERENCES}

1. Regional strategy for the prevention and control of viral hepatitis. CD_282.pdf. Available at: http://www.searo.who.int/entity/emerging_diseases/t opics/CD_282.pdf. Accessed 30 June 2019.

2. Batham A, Narula D, Toteja T, Sreenivas V, Puliyel JM. Sytematic review and meta-analysis of prevalence of hepatitis B in India. Indian Pediatr. 2007;44(9):663-74.

3. Operational_Guidelines_for_HepatitisB_vaccine_intr oduction_in_UIP_2011.pdf Available at: http://www.searo.who.int/india/topics/routine_immu nization/Operational_Guidelines_for_HepatitisB_vac 
cine_introduction_in_UIP_2011.pdf?ua=1. Accessed 30 June 2019.

4. Nguyen TH, Vu MH, Nguyen VC, Nguyen LH, Toda K, Nguyen TN, et al. A reduction in chronic hepatitis B virus infection prevalence among children in Vietnam demonstrates the importance of vaccination. Vaccine. 2014;32(2):217-22.

5. India: WHO and UNICEF estimates of immunization coverage: 2017 revision. ind.pdf. Available at: https://www.who.int/immunization/monitoring_surv eillance/data/ind.pdf. Accessed 30 June 2019.

6. Jha S, Devaliya D, Bergson S, Desai S. Hepatitis B knowledge among women of childbearing age in three slums in Mumbai: a cross-sectional survey. Hepatol Med Policy. 2016;1(1):5.

7. ul Haq N, Hassali MA, Shafie AA, Saleem F, Farooqui M, Haseeb A, et al. A cross-sectional assessment of knowledge, attitude and practice among Hepatitis-B patients in Quetta, Pakistan. BMC Public Health. 2013;13(1):448.

8. Pham TT, Le TX, Nguyen DT, Luu CM, Truong BD, Tran PD, et al. Knowledge, attitudes and practices of hepatitis B prevention and immunization of pregnant women and mothers in northern Vietnam. Plos One. 2019;14(4):e0208154.

9. Adeyemi AB, Enabor OO, Ugwu IA, Bello FA, Olayemi OO. Knowledge of hepatitis B virus infection, access to screening and vaccination among pregnant women in Ibadan, Nigeria. J Obstet Gynaecol. 2013;33(2):155-9.
10. Han Z, Yin Y, Zhang Y, Ehrhardt S, Thio CL, Nelson KE, et al. Knowledge of and attitudes towards hepatitis B and its transmission from mother to child among pregnant women in Guangdong Province, China. PLos One. 2017;12(6):e0178671.

11. World Health Organization, Global Hepatitis Programme. WHO guidelines on hepatitis B and C testing. 2017. Available at: http://apps.who.int/iris/bitstream/10665/254621/1/97 89241549981-eng.pdf. Accessed 4 Jul 2019.

12. Dam L, Cheng A, Tran P, Wong SS, Hershow R, Cotler S, et al. Hepatitis B Stigma and Knowledge among Vietnamese in Ho Chi Minh City and Chicago. Can J Gastroenterol Hepatol. 2016; 2016:1910292.

13. ul Haq N, Hassali MA, Shafie AA, Saleem F, Aljadhey H. A cross sectional assessment of health related quality of life among patients with Hepatitis$B$ in Pakistan. Health Qual Life Outcomes. 2012;10(1):91.

Cite this article as: Munivenkatappa S, Govindaraj SM. A study evaluating knowledge of and attitude towards hepatitis B among pregnant women at a teaching hospital in Nellore, India. Int J Reprod Contracept Obstet Gynecol 2019;8:3183-8. 